\title{
Endocrine paraneoplastic syndromes: a review
}

\begin{abstract}
Paraneoplastic endocrine syndromes result from ectopic production of hormones by different tumors. Hypercalcemia of malignancy is the most common, mostly caused by ectopic parathyroid hormone related peptide $(\mathrm{PTHrP})$ production which increases bone resorption. Other causes include the rare ectopic parathyroid hormone (PTH) production, ectopic production of $1,25-(\mathrm{OH})_{2}$ vitamin $\mathrm{D}$ by the tumor and its adjacent macrophages and bone metastasis which by itself in addition to the local production of PTHrP at the level of the bone lead to bone resorption and thus hypercalcemia. Treatment includes extracellular fluid volume repletion, bisphosphonates or denosumab and calcitonin. Ectopic Cushing's syndrome caused by ectopic ACTH production results in hypokalemia, proximal muscle weakness, easy bruisability, hypertension, diabetes and psychiatric abnormalities including depression and mood disorders. Different diagnostic measures help to differentiate Cushing's disease from ectopic Cushing's syndrome. Treatment includes surgical resection of tumor and medical therapy to suppress excess cortisol production. Ectopic secretion of $\mathrm{ADH}$ has been associated with different tumor types. The best treatment options include removal of the underlying tumor, chemotherapy, or radiotherapy in addition to free water restriction, demeclocycline and vaptans. Ectopic growth hormone releasing hormone secretion has been identified with carcinoids, phechromocytoma and other tumors. Surgery is the mainstay of therapy with systemic therapy used in metastatic disease. Other rare ectopic hormone syndromes have also been identified including ectopic prolactin, ectopic erythropoietin, thrombopoetin in addition to others.
\end{abstract}

Keywords: paraneoplastic endocrine syndromes, hypokalemia, cushing's disease, PTHrP, ACTH
Volume I Issue I - 2015

\author{
Hala Ahmadieh,' Asma Arabi² \\ 'Division of Endocrinology, American University of Beirut, \\ Lebanon \\ ${ }^{2}$ Department of Internal Medicine, American University of \\ Beirut-Medical Center, Lebanon
}

\begin{abstract}
Correspondence: Asma Arabi, Department of Internal Medicine, Division of Endocrinology, American University of Beirut-Medical Center, Po Box I I-0236, Riad El-Solh, Beirut,
\end{abstract} Lebanon,Email Aa22@aub.edu.lb

Received: October 26, 2014 | Published: January 02, 2015

\begin{abstract}
Abbreviations: RANKL, receptor activator of nuclear factorkappa B ligand; PTHrP, parathyroid hormone related peptide; ACTH, adrenocorticotropic hormone; POMC, pro-opiomelanocortin; PNES, paraneoplastic endocrine syndrome; OPG, osteoprotegnin; CS, cushing's syndrome; CLIP, corticotrophin-like intermediate lobe peptide; MSH, $\alpha$-melanocyte stimulating hormone; CLIP, corticotrophin-like intermediate lobe peptide; EAS, ectopic ACTH syndrome; NSE, neuron-specific enolase; GHRH, Growth hormone releasing hormone; ADH, Antidiuretic hormone; AVP, arginine vasopressin; SIADH, syndrome of inappropriate ADH secretion; GHRH, growth hormone releasing hormone; $\mathrm{CRH}$, corticotropin releasing hormone; PRL, prolactin; CEA, carcinoembryonic antigen
\end{abstract}

\section{Introduction}

The paraneoplastic endocrine syndromes (PNES) occur as a result of the production of hormonal substances by different tumors leading to the manifestation of unique clinical endocrine syndromes. Development of these disorders does not often necessarily correlate with the cancer stage or prognosis and may even occur before the diagnosis of cancer is made.

For the diagnosis of ectopic hormone syndromes to be made, there must be clinical or biochemical evidence of an endocrine abnormality in a patient with neoplastic disease, without any concomitant native endocrine organ dysfunction that might explain the syndrome as well. Endocrine syndrome often disappears after tumor removal, suggesting that the tumor was the source of the ectopic hormone production. A high hormonal arteriovenous gradient is usually present across the tumor. However owing to practical reasons and the unpredictable hormone secretion by the tumor, this criterion is not always available. Moreover the lack of precision and the fact that the hormone assays are sensitive may cause problems in evaluating the results as well. Tumor cells that are cultured may be capable of synthesizing the hormone or contain higher concentration of hormone-specific mRNA. However, it is important to mention that even normal non-endocrine tissues are capable of producing hormones, such as the production of propiomelanocortin (POMC) by certain non-endocrine tissues. Treatment of the malignancy itself is the mainstay of treatment of paraneoplastic endocrine syndromes, along with other supportive measures such as fluid resuscitation or electrolyte disturbance correction. ${ }^{1}$

It is important for the endocrinologist and oncologist to recognize these paraneoplastic endocrine syndromes since this may help in defining the cancer type and hence lead to the appropriate management. In addition, these syndromes are a major cause of morbidity and mortality. Moreover, paraneoplastic endocrine syndromes may be the first presenting feature of malignancy. ${ }^{2,3}$

This paper provides an overview on the common PNES, their prevalence, diagnosis, prognosis and response to treatment. (Table 1)

\section{Methodology of literature search}

Eligible studies were identified by a search, from year 1920 up till February 2014, in Medline, PUBMED and EMBASE using a refined search strategy with several terms used including "endocrine paraneoplastic syndromes", "ectopic hormones", "humoral hypercalcemia of malignancy", "ectopic parathyroid hormone related peptide", "ectopic ACTH", "ectopic Cushing syndrome", “ectopic 
antidiuretic hormone", "syndrome of inappropriate ADH", "ectopic growth hormone releasing hormone", "ectopic growth hormone", "ectopic prolactin", "ectopic thyroid stimulating hormone" in addition to several others. In addition, searches of personal collections and the reference lists of eligible studies were identified with their full text papers being retrieved.

Table I The most common tumoral sources and features of ectopichormones

\begin{tabular}{|c|c|c|}
\hline Ectopic hormones & Tumor types & Characteristics and specific features \\
\hline $\begin{array}{l}\text { Parathyroid hormone } \\
\text { related peptide }\end{array}$ & $\begin{array}{l}\text { Squamous cell cancer of the lung, head \& } \\
\text { neck, esophagus, cervix, vulva, skin, renal } \\
\text { cell cancers, breast cancers, other solid } \\
\text { tumors (ovarian, bladder, adenocarcinoma, } \\
\text { large cell lung carcinoma), Neuroendocrine } \\
\text { tumors(islet cells, pheochromocytoma), } \\
\text { multiple myeloma. lymphoma, adult T cell }\end{array}$ & $\begin{array}{l}\text { Because of the rapid increase in calcium level, symptoms are very } \\
\text { common. Most of the symptoms are related to gastrointestinal tract. } \\
\text { In addition, thirst, nocturia, polyuria and dry mouth reflected by the } \\
\text { disturbances in water metabolism. Symptoms related to the nervous } \\
\text { system including drowsiness and blurred vision may also occur. }\end{array}$ \\
\hline
\end{tabular}
leukemia.

Bronchial Carcinoids, small cell lung cancer, Islet cell tumors of pancreas/pancreatic carcinoids, thymic Carcinoids, medullary thyroid cancer, pheochromocytoma,other neuroendocrine tumours (gastrinoma, primary hepatic carcinoid, etc...)

Small cell lung cancer and other lung cancers, Gl tumors (duodenal, pancreatic, etc...), Head \& neck cancer (mainly oral cavity), Others (case reports) includes primary \& metastatic brain tumor, thymus tumors, prostate, bladder, uterine, cervical tumors, hematologic malignancies \& other occult tumors

\section{GHRH}

Bronchial and pancreatic carcinoid tumors, pheochromocytoma, lung cystic adenoma

Prolactin malignant tumours of the lung, kidney, uterine, ovary, breast and colorectal cancer
Rapid onset and progression of Cushing syndrome. Hypokalmeic metabolic alkalosis, hypertension and hyperpigmentation are common. Psychiatric disorders are more prominent in neuroendocrine tumors.

Varyfrom asymptomatic to deeply comatoseaccording to the severity andparticularly to the rapidity of onset of change in the plasmasodium concentration.

Nausea and malaise are the earliest findings followed by

headache,lethargy and obtundation and seizures.

Hyponatremicencephalopathy may be reversible; however

permanentneurologic damage or death may occur.

Very rare condition. Clinical signs and symptoms are closely related to patients with acromegaly due to $\mathrm{GH}$ secreting piryuitary adenoma.

Bad prognosis in certain tumor types such as colorectal cancers.

\section{Hypercalcemia of malignancy}

Historical perspective: The first description of the term 'hypercalcemia of malignancy' occurred in 1924. ${ }^{4}$ Then in 1936, a case of a 57-year-old male with bronchogenic carcinoma with marked hypercalcemia, not associated with metastases as evident radiologically or at postmortem, and with normal parathyroids, was reported by Gutman et al. who attributed the cause to "complicating factors as yet wholly obscure. " In 1941, Albright reported another case of a 51 year old man with lytic lesion in his right ilium, which was metastatic from renal cell carcinoma, who had hypercalcemia \& hypophosphatemia. Hypercalcemia resolved after irradiation of this single bone metastasis. Since lysis of bone is expected to liberate both calcium and phosphate, Albright suggested that tumor was producing parathyroid hormone (PTH) and the term ectopic PTH syndrome was used. ${ }^{6}$ But then with the improvement of PTH radioimmunoassay in the 1970s, some doubt arose regarding PTH being the cause for this syndrome. The term " humoral hypercalcemia of malignancy" was first proposed in 1979 by Martin and Atkins, in patients who exhibited increased renal production of cAMP with a low or undetectable plasma levels of PTH. ${ }^{7}$ Sensitive bioassays were able to identify and purify this 'PTH-like factor' which later was called parathyroid hormone related peptide (PTHrP). Its sequence was finally obtained in 1987, from a cultured human squamous cell line, obtained from a patient who had hypercalcemia. ${ }^{8}$

\section{Prevalence, presentation and diagnosis}

Hypercalcemia of malignancy is the most common PNES, where it is estimated to occur in up to $30 \%$ of patients with cancer at some point during their course of disease. It is the most common cause of hypercalcemia in hospitalized patients as opposed to primary hyperparathyroidism being the most common cause of hypercalcemia in community at large. It conveys a poor prognosis, where in a retrospective study of 126 patients with cancer-associated hypercalcemia, the median survival did not exceed 30 days. ${ }^{9}$ In a cohort of 252 patients, a prognostic score including liver metastasis, squamous cell carcinoma, hypoalbuminemia, and calcemia $>2.83$ mmol was developed, for the prediction of 90-day mortality in patients with hypercalcemia of malignancy, and it was found that those patients who had a score of 0 experienced a median overall survival of 797 days as opposed to those having a score of $\geq 1$, who were shown to have a median survival of 49 days only. ${ }^{10}$ Hypercalcemia of malignancy occurs most commonly in primary tumors of lung, breast, head and neck, kidney and ovary. Hematological malignancies can be complicated by hypercalcemia as well, where up to one third of patients with multiple myeloma were found to have high calcium levels. Malignancy associated hypercalcemia is rapidly progressive and symptoms tend to occur at lower plasma concentrations of 
calcium, where it was estimated that around $50 \%$ of patients develop neurological manifestations. ${ }^{11}$ The causes of death in these patients is mainly related to the complications of hypercalcemia such as coma, renal failure, and to the progression of tumor itself. ${ }^{11}$

\section{Pathophysiology}

There are four principal mechanisms of hypercalcemia in cancer patients. ${ }^{11-12}$ (Table 2) Parathyroid hormone releasing peptide (PTHrP) secretion by tumor cells, accounts for $80 \%$ of cases and occurs with squamous cell tumors mainly. ${ }^{13-16} \mathrm{PTHrP}$ is a small peptide, which resembles parathyroid hormone (PTH) where 8 of its first 16 amino acids are homologous to PTH. Like parathyroid hormone (PTH), the bioactivity of PTHrP resides mainly in these first eight amino acids. PTHrP acts on the kidney causing an increase in proximal tubular reabsorption of calcium. Indeed, it is common to ascribe the clinical syndrome of PTHrP production to hyperparathyroidism, until the identification of a suppressed parathyroid hormone blood level. It is also capable of binding to PTH type 1 receptors normally located in bones, leading to increased bone resorption. It also enhances the production of RANK ligand (RANKL) by osteoblastic stromal cells, which acts as a powerful inducer of osteoclast formation and differentiation. ${ }^{17-20}$ PTHrP also inhibits the production of osteoprotegerin (OPG). OPG is a secreted member of the tumor necrosis factor (TNF) receptor family that is produced by osteoblastic stromal cells, and is capable of inhibiting osteoclast formation. PTHrP, by inhibiting OPG production, would actually lead to increased osteoclast formation and differentiation and hence increased bone resoprtion. Indeed, it is common to ascribe the clinical syndrome of PTHrP production to hyperparathyroidism, until the identification of a suppressed parathyroid hormone blood level. It is important to mention that although PTHrP resembles PTH in its action in general, however it is not known to increase $1 \alpha$-hydroxylase activity like parathyroid hormone does and hence $1,25-(\mathrm{OH}) 2 \mathrm{D}$ production does not increase in cases of hypercalcemia of malignancy when it is attributed to PTHrP production. ${ }^{11}$

Table 2 Mechanisms leading to hypercalcemia of malignancy

Pathophysiology of hypercalcemia of malignancy

Ectopic parathyroid hormone releasing peptide secretion by tumors accounts $(80 \%)$

Skeletal Metastases secondary to local osteolysis and to local PTHrP secretion (15\%)

Excessive secretion of I,25-dihydroxyvitamin D by malignancies such as lymphoma $(<5 \%)$

Rarely caused by ectopic Parathyroid hormone production (<1\%)

Extensive bone metastasis by the cancer cells would lead to local osteolysis and bone destruction. This accounts for approximately $20 \%$ of all the cases of hypercalcemia associated with malignancy. But recently there was growing body of evidence which revealed the importance of the local production of PTHrP by the invading cancer cells, which led to around $80 \%$ of causes of hypercalcemia in such patients with metastatic bone disease, especially in patients with breast cancer who had skeletal metastasis. ${ }^{21}$ Therefore local PTHrP production might contribute to the ability of breast cancers to erode bone and cause metastases. ${ }^{22-24}$ PTHrP levels were also found to be elevated in $64 \%$ of patients with hypercalcemia who had metastatic malignancy to bone from primary sources other than the breast tissue. Prostate cancers can also metastasize to bone leading to osteolytic and/or osteoblastic lesions as well. ${ }^{25-26}$

Human T-cell leukemia virus type 1 (HTLV-1) associated adult T-cell leukemia/lymphoma was also associated with humeral hypercalcemia of malignancy. ${ }^{11}$

Hypercalcemia was also found to occur in one-third of multiple myeloma patients. These patients were found to have increased bone resorption by the normal osteoclasts residing in the areas near to the myeloma cells. ${ }^{27}$ This suggested that myeloma cells secrete factors that stimulate osteoclast action. Several cytokines have been postulated to be responsible for the increased bone resorption. These included TNF alpha, IL-1, and IL-6. Elevated PTHrP levels were found in one-third of patients with multiple myeloma who have hypercalcemia. PTHrP can be added to the list of cytokines contributing to the bone loss and hypercalcemia in patients with multiple myeloma. ${ }^{28}$

As noted PTHrP is responsible for the vast majority of of humoral hypercalcemia of malignancy cases, however, rare cases have reported ectopic PTH secretion by tumors, where the suspicion of such cases should arise in a patient with a known malignancy that has an elevated calcium and PTH, and when a standard technetium $(99 \mathrm{mTc})$ sestamibi scan does not identify a parathyroid adenoma in the neck. ${ }^{11-12}$

Hematological malignancies may also be associated with hypercalcemia, due to the excessive secretion of 1,25-dihydroxyvitamin $\mathrm{D}$, leading to the increased gastrointestinal absorption of calcium. This has been described in around half of all patients with lymphoma who were found to have hypercalcemia. In these patients, $1 \alpha$-hydroxylase was found to be produced by tissue neighboring macrophages and by the lymphomatous tissues themselves. ${ }^{29}$ these patients often have a normal or slightly increased phosphorus level (caused by the suppression of PTH production and increased phosphate reabsorption by the1,25-dihydroxyvitamin D), hypercalcemia and hypercalciuria, absence of bone metastasis, and an elevated serum calcitriol level.

\section{Treatment}

Dehydration is a common finding in hypercalcemic patients in general. Therefore the initial management of malignancy associated hypercalcemia does not differ from the management of other causes of hypercalcemia. It should include fluid resuscitation in the first instance with the infusion of a solution of normal saline at rates ranging between 100 and $300 \mathrm{~mL} / \mathrm{h}$. This will normally lower the serum calcium by $10 \%$ to $40 \%$ over a period of 6 to $12 \mathrm{~h}$. Loop diuretics can also facilitate renal calcium excretion through inhibition of calcium reabsorption in the thick ascending limb of the loop of Henle, but should only be used after adequate hydration was done, otherwise dehydration will be worsened. . $^{13,30-32}$

\section{Bisphosphonates}

Patients with severe hypercalcemia, with a serum calcium concentration level above $13 \mathrm{mg} / \mathrm{dL}$, or those who have an altered level of consciousness or evidence of renal dysfunction attributable 
to hypercalcemia, should also be treated with bisphosphonates in addition to the generous intravenous hydration. Bisphosphonates suppress bone resorption by causing osteoclast apoptosis after inducing changes in its cytoskeleton. ${ }^{34-36}$ They also induce apoptosis of tumor cells as shown by different in vitro and animal studies. ${ }^{37-39}$ The bisphosphonates calcium lowering response was unfortunately shortlived and serum calcium usually returns to its high basal values within 2-4 weeks of discontinuing treatment in untreated malignancy cases. Pamidronate has been the most widely investigated bisphosphonate in the management of malignancy-associated hypercalcemia, with the recommended single dose of $90 \mathrm{mg}$, which was shown to achieve normocalcemia in up to $90 \%$ of patients regardless of tumor type or the presence or absence of bone metastases. ${ }^{40-42}$ A recently published large multicenter double-blind study compared the efficacy of zoledronate and pamidronate in patients with malignancy-associated hypercalcemia and showed the superiority of zoledronate, which was administered as a single 5-min infusion of $4 \mathrm{mg}$ (as initial treatment) or $8 \mathrm{mg}$ (for relapsed or refractory hypercalcemia), as compared to pamidronate which was administered as a single 2-h infusion of the 90-mg dose. Zoledronate and pamidronate given at the above doses were found to decrease serum calcium concentrations to $2.7 \mathrm{mmol} / \mathrm{L}$ or below in $88 \%$ and $70 \%$ of patients, respectively. Zoledronate had also a longer lasting effect than pamidronate (30 days versus 17 days, respectively). There was, however, no difference in the retreatment response rate, which was $52 \%$ for both bisphosphonates. ${ }^{43}$ Therefore, many clinicians prefer zoledronic acid for such cases. The bisphosphonate ibandronate is not yet approved by the FDA for this indication. ${ }^{44}$ Disadvantages of bisphosphonates include renal toxicity which can be minimized with dose adjustment, osteonecrosis of the jaw, especially in patients with poor dentition and the risk of atypical fracture of the femur. ${ }^{45-46} \mathrm{It}$ is important to note that severe or refractory hypercalcemia which is unresponsive to different therapies is an indicator of poor prognosis.

\section{Denosumab}

Densoumab, a human monoclonal antibody targeting RANKL ligand, was first approved by the U.S. Food and Drug Administration (FDA) for its use in postmenopausal women with osteoporosis. Then in November 2010, it was used for the prevention of skeleton-related events in patients with solid tumors and bone metastases.47-48 Denosumab was found to be superior to zoledronic acid in delaying or preventing skeletal-related events in patients with breast cancer who had metastases to bone. ${ }^{49}$ In 2011, several clinical trials were undergone for investigating its role in giant cell tumors, multiple myeloma with bone metastases, and hypercalcemia of malignancy.

A series of seven patients who received doses of denosumab for hypercalcemia of malignancy was reported. In this series the most common tumor types were breast cancer $(n=3)$ and hematologic malignancies $(n=2)$. All patients had bone involvement. Two of those patients received single doses of denosumab, the $60 \mathrm{mg}$ dose, but the other five patients received the $120 \mathrm{mg}$ dose. In these patients denosumab was found to be effective in decreasing serum calcium level. However, symptomatic hypocalcemia may result from denosumab when used in the treatment of hypercalcemia of malignancy. ${ }^{50}$

In another recent study, patients with advanced cancer who had persistent hypercalcemia after having an incomplete response or relapse with bisphosphonate treatment, denosumab was shown to effectively lower serum calcium to grade 1 or lower $(\leq 11.5 \mathrm{mg} / \mathrm{dL})$ in
$80 \%$ of patients with a maintained response for a median of 26 days. This was a clinically meaningful outcome especially for patients who entered this study with grade 3 hypercalcemia after only 18 days of receiving the last dose of intravenous bisphosphonate. ${ }^{51}$

\section{Calcitonin}

Since calcitonin receptors are expressed on the membrane surface of mature osteoclasts, and since receptor activation directly and potently inhibits osteoclast function, calcitonin was used for hypercalcemia of malignancy and is known for its rapid calciumlowering effect, which is maximal ${ }^{4-6} \mathrm{~h}$ after injection. The effect of calcitonin is short-lived, where serum calcium generally returns to pretreatment levels within 24 hours. As calcitonin acts rapidly but its effect is not sustained, maximum beneficial effect is obtained by combining this agent with a slower-acting bisphosphonate. The recommended dose of calcitonin is 200 to 400 units intramuscularly or subcutaneously every 12 hours. ${ }^{52-53}$

\section{Glucocorticoids}

Glucocorticoids are useful in the management of patients with hematological malignancies, especially multiple myeloma patients because of their ability to reduce the synthesis of bone-resorbing cytokines. They may inhibit the growth of neoplastic lymphoid tissue in lymphoreticular malignancies. They may reduce the production of the active metabolite of vitamin $\mathrm{D}$, hence normalizing serum calcium in lymphomas patients by blocking its effects on intestinal absorption of calcium. ${ }^{54}$ Prednisone at a dose of $40-60 \mathrm{mg}$ daily is typically effective. However it is important to note that if no appreciable response is observed within 10 days, then glucocorticoid therapy should be discontinued. Moreover there is a risk of inducing iatrogenic Cushing with the extensive use of steroids. ${ }^{55}$

\section{Ectopic cushing syndrome}

\section{Prevalence, presentation and diagnosis}

Inappropriate secretion of ACTH in certain types of malignancies is uncommon but still is an important cause of morbidity and mortality. $20 \%$ of cases of ACTH dependent Cushing's syndrome are due to ectopic ACTH syndrome (EAS) secretion. Small cell lung cancers, medullary thyroid cancers and bronchial carcinoids represent the tumors that are most commonly associated with ectopic ACTH syndrome..$^{56}$ The previous literature reported the high prevalence of ectopic ACTH syndrome caused by small cell lung carcinoma but recently there has been shift towards neuroendocrine tumors contributing to the ectopic ACTH syndrome particularly the bronchial carcinoids. Other tumors that are less likely to be associated with EAS include islet cell tumors of the pancreas or pancreatic carcinoids, thymic carcinoids, and gastrinomas..$^{57-59}$

Occult tumors, defined as those that cannot be identified even after a meticulous diagnostic workup is done, contributed to $12-37.5 \%$ of ectopic ACTH syndrome cases. ${ }^{56-59}$ Lung and neck are the main sites of ectopic ACTH syndrome. ${ }^{57-59}$ Tumor size ranged from $0.3 \mathrm{~cm}$ to 7 $\mathrm{cm} .{ }^{60}$ Presenting symptoms are similar to those of Cushing disease. Psychiatric disorders are more prominent in neuroendocrine tumors. ${ }^{58-60}$ The rapid onset and progression of Cushing syndrome may suggest ectopic ACTH syndrome production. ${ }^{57-60}$ Diagnosis of ectopic ACTH syndrome occurs earlier in small cell lung carcinoma and pancreatic islet cell tumors because of the early appearance of symptoms related to ectopic ACTH production, as compared to bronchial carcinoids 
which are more indolent and hence are diagnosed at a later stage. ${ }^{61-62}$ The experience with patients who had ectopic Cushing syndrome, during the years 1985 to 2006 , were retrospectively reviewed at a tertiary care center in Chandigarh. It was found that weight loss $(41.7 \%)$ was the most common symptom followed by infections $(16.7 \%)$. Hypertension (100\%), easy bruisability $(92 \%)$ and proximal myopathy $(83 \%)$ were the most common signs. ${ }^{60}$ Hyperpigmentation was also reported to occur in around $25 \%$ of those patients. ${ }^{60}$

The hallmark of ectopic ACTH syndrome is the finding of an increased plasma ACTH concentration, where a plasma ACTH concentration greater than $100 \mathrm{pg} / \mathrm{mL}$ should prompt investigation for an ectopic source of ACTH. However, the differentiation between pituitary ACTH production and ectopic tumor production of ACTH or ectopic CRH production is a very difficult task. The oncologist who is confronted with a patient with a malignant neoplasm and clinical features of Cushing syndrome should not assume that these clinical features are due to a diagnosis of ectopic ACTH syndrome without considering other diagnostic possibilities including a pituitary $\mathrm{ACTH}$ producing tumor. The diagnosis of ectopic ACTH syndrome can be made after the demonstration of ACTH immunohistochemical staining in the tumor tissue or in its metastatic deposits and/or reversal of the clinical syndrome, with complete/partial resolution of the hypercortisolemia syndrome after tumor resection, if a tumor was identified in the first place. Pituitary adenomas are known to retain some responsiveness to the negative feedback effects of glucocorticoids, as opposed to ectopic tumors. ${ }^{62-63}$ The corticotropin-releasing hormone (CRH) test done either alone or in combination with desmopressin in addition to the high-dose dexamethasone test (HDDST) are the two most commonly used dynamic tests to separate between the available entities. Endogenous cortisol production which is not be suppressed with the administration of high-dose dexamethasone and could not be stimulated with the administration of corticotropin-releasing hormone, suggest the diagnosis of Cushing's syndrome resulting from the ectopic secretion of corticotropin. ${ }^{60-63}$ The next step in the diagnostic work-up depends on the availability of bilateral inferior petrosal sinus sampling (BIPSS) with CRH stimulation, which also can help in the differentiation of causes of ACTH-dependent CS. (6466) On the other hand, all patients of ectopic Cushing's syndrome had a ratio of $<2$ with a specificity of $100 \%$. BIPSS helped in localization of the lesion and improved the diagnostic yield from $26.7 \%$ to $73.5 \% .{ }^{67}$

The source of ectopic ACTH secretion should be established because the excision of an ACTH producing

tumor can be curative. Conventional imaging studies, such as CT and MRI, may identify the tumor in only $50 \%$ of cases. ${ }^{63}$ Functional imaging studies such as PET and somatostatin receptor scintigraphy (SRS) are complementary imaging tools. ${ }^{68-70}$ Somatostatin receptor scintigraphy might be considered superior to PET in detecting bronchial carcinoids, especially that these tumors specifically are known to have low proliferation index. ${ }^{69-70}$

\section{Characterization of ACTH related peptides in ectopic Cushing 's syndrome}

$\mathrm{ACTH}$ is formed as part of pro-opiomelanocortin (POMC), which is cleaved by prohormone convertase (PC) 1 at the $C$-terminal of ACTH to give $\beta \mathrm{LPH}$ and then it cleaves the $N$-terminal of ACTH. Cleavage to smaller peptides occurs by the action of prohormone convertase 2(PC2) with further post-translational modification to produce $\alpha$-melanocyte stimulating hormone ( $\alpha \mathrm{MSH})$. The extent of POMC processing is tissue dependent. In the anterior lobe of the pituitary, the presence of $\mathrm{PC} 1$ and the absence of $\mathrm{PC} 2$ results in $\mathrm{ACTH}$ as the major secretory product. ${ }^{71}$ Although having an ACTH level above $200 \mathrm{ng} / \mathrm{l}$ is more common in ectopic CTH syndrome, no threshold are definite for the distinction between EAS and Cushing disease. ${ }^{72-73}$ Retrospective analysis of 86 patients found that measurement of mature ACTH was not helpful in the differential diagnosis between patients with pituitary-dependent Cushing's disease and the ectopic ACTH syndrome. However measurement of ACTH precursors was helpful, as all patients with ectopic tumors that secrete ACTH were also found to secrete ACTH precursor levels in the range 139-18,000 $\mathrm{pmol} / \mathrm{l}$, which were significantly higher than patients with pituitarydependent Cushing's disease (9-104 pmol/1). Patients with carcinoid tumors also had ACTH precursor concentrations more than $100 \mathrm{pmol} / 1$. Therefore using $100 \mathrm{pmol} / 1$ as the diagnostic cut-off has $97 \%$ percent sensitivity and $100 \%$ specificity. (74) A previous study using an assay for POMC alone, found good discrimination between ectopic and pituitary tumors. The levels of POMC in 19/19 patients with pituitary microadenomas were low, as opposed to being elevated in $16 / 20$ patients with ectopic ACTH syndrome. The remaining four patients with ectopic tumors had undetectable levels of POMC and were later found to have bronchial carcinoid tumors. ${ }^{75}$ This suggests that some carcinoid tumors are capable of processing POMC to ACTH. It is also suggested that further processing may occur since a $\mathrm{C}$-terminal fragment of $\mathrm{ACTH}$, termed corticotrophin-like intermediate lobe peptide (CLIP) has been detected in three bronchial carcinoid tumor extracts but were not found to be present in the peripheral circulation. ${ }^{76}$

Some lab tests and biochemical markers help to differentiate between ectopic ACTH syndrome and Cushing's disease. These include hypokalemia and some tumor markers. ${ }^{72-73}$ Hypokalemia was reported in $42-70 \%$ of patients with ectopic ACTH syndrome. . $^{5-60}$ Tumor markers may be elevated with neuroendocrine tumors. ${ }^{60,77-78}$ Calcitonin, for example, was noted to be lower in patients with Cushing's disease as compared to patients with ectopic ACTH syndrome, where it was found to be increased in $75 \%$ of patients with overt tumors and in $38 \%$ patients with occult tumors. ${ }^{60,78-79}$ Other useful tumor markers include gastrin, glucagon, pancreatic polypeptide and others, where at least one of these tumor markers is found to be increased in $72 \%$ of patients with EAS. ${ }^{72,77-79}$

\section{Treatment}

Surgical excision of the primary lesion is the best treatment of all ectopic ACTH syndromes. In such cases complete remission can be achieved in up to $83 \%$ of patients. It may also be useful to do multiple surgical excisions in cases of multiple recurrences. ${ }^{56-58,80}$ Adrenalectomy (unilateral or radical) remains an option if hypercortisolism cannot be controlled by medical therapy and if the tumor secreting ectopic ACTH cannot be resected in the first place. ${ }^{57,60}$ Adrenal blocking drugs via inhibition of steroidogenic enzymes are an effective medical treatment for patients with ectopic Cushing syndrome who are not amenable to surgical therapy or for those awaiting surgery to be done. Ketoconazole and metyrapone are the most frequently used drugs but their use may be limited due to their side effects like hepatotoxicity, seen with ketoconazole therapy, and the increased androgen and mineralocorticoid production noted with metyrapone. ${ }^{80}$ Moreover appropriate medical therapy in small cell lung cancer is necessary for the immediate correction of hypercortisolism in order to minimize the side effect of myelosuppressive cytotoxic chemotherapy. ${ }^{79-80}$ Etomidate infusions have been successfully used when rapid control of hypercortisolaemia in severely-ill patients with EAS. ${ }^{81}$ Because 
tumors secreting ectopic ACTH may exhibit dopamine receptors or somatostation receptors, somatostatin analogues or dopamine agonists were occasionally used either alone or as add on therapy to inhibitors of steroid synthesis in patients with incomplete resection and in those with recurrences ${ }^{82-83}$ In carcinoids causing ectopic ACTH syndrome external radiotherapy can also be utilised. ${ }^{78}$

\section{Prognosis}

The predictors of the prognosis of ectopic ACTH syndromes include tumor histology and the severity of signs and symptoms of hypercortisolism, which were found to be associated to increased morbidity and mortality. This was mainly due to infections, peritonitis, increased risk of pulmonary embolism and heart failure. Bronchial carcinoids tend to have a good prognosis while small cell lung cancer and thymic carcinoids are noted for their bad prognosis. ${ }^{77-78}$

\section{Syndrome of inappropriate ADH secretion (SIADH)}

Historical perspective: The first clinical case of a patient with SIADH was presented by Schwartz et al., ${ }^{84}$ when he described two patients with lung cancer who developed hyponatremia associated with continued urinary sodium loss. They postulated that the tumors led to the inappropriate release of antidiuretic hormone (ADH), later discovered to consist of AVP. (84-85) This was later confirmed since immunoactive AVP has been noted to be elevated in the plasma of patients with bronchogenic carcinoma and in patients with cancers of the digestive tract. ${ }^{85-86}$

\section{Prevalence, presentation and diagnosis}

About $14 \%$ of hyponatremia cases found in admitted patients is attributed to an underlying tumor. It usually accompanies but can precede the diagnosis of the tumor with an incidence of about $3.7 \%$ to $5 \%$. (86) Syndrome of inappropriate ADH secretion is the most common cause of hyponatremia in this population. ADH is synthesized in the hypothalamus and transported down the pituitary stalk to the posterior pituitary, where it is stored. ADH binds to V2 receptors on the cells lining the collecting tubules in the kidney facilitating water reabsorption in the renal medulla. Some tumors may actually demonstrate multiple hormone production such as ectopic secretion of adrenocorticotropic hormone and ADH. ${ }^{87}$ Ectopic secretion of ADH has been associated with small cell lung cancer, bronchogenic carcinoma, duodenal tumors, pancreatic tumors, thymus tumors, olfactory neuroblastoma, sarcoma, malignant histiocytosis, mesothelioma as well as other occult tumors. ${ }^{87-90}$

The signs and symptoms of SIADH depend on both the degree of hyponatremia and the rate at which it develops. A serum sodium concentration less than $120 \mathrm{mEq} / \mathrm{L}$ or serum osmolality less than 240 $\mathrm{mOsm} / \mathrm{kg}$ is considered serious, irrespective of the rate of decline and patients can experience cerebral edema, permanent brain damage, brainstem herniation, or death. ${ }^{89}$

The key points in diagnosing SIADH are the findings of a plasma osmolality less than $280 \mathrm{mosmol} / \mathrm{kg}$, hyponatremia with a plasma sodium concentration of less than $134 \mathrm{mmol} / \mathrm{l}$, hypotonicity, inappropriate increased urinary concentration with a urine osmolality of more than $100 \mathrm{mosmol} / \mathrm{kg}$ ), and an elevated urine sodium concentration of more than $40 \mathrm{mmol} / \mathrm{l}$. However it is important to note that a low urine sodium concentration does not exclude the diagnosis. Patients with SIADH are clinically euvolemic. Hypouricemia occasionally may be associated with SIADH as a result of increased excretion of nitrogen waste and plasma dilution. ${ }^{90}$

SIADH is usually one of the most common causes of euvolemic hyponatremia. However other causes of euvolemic hyponatremia in these patients include inappropriate hypotonic fluid replacement, particularly following surgeries or diarrheal illnesses. (91-95) ACTH deficiency needs to be ruled out as well, since cortisol is necessary for the efficient excretion of free water, and glucocorticoid deficiency is usually associated with the retention of free water and thus hyponatraemia leading to a picture identical to SIADH. These patients often have as well elevated plasma arginine vasopressin (AVP) concentrations, which contributes further to the tubular reabsorption of water. ${ }^{96}$

\section{Treatment}

Fluid restriction and occasionally furosemide with salt supplementation are the recommended adjunctive therapy for severe hyponatremia. However the best treatment is the removal of the underlying tumor, or at least reduction of tumor mass by surgery, chemotherapy, or radiotherapy. Treatment with demeclocycline (150 to $300 \mathrm{mg} / \mathrm{d}$ ) inhibits the effects of vasopressin on the kidney and is the preferable long-term treatment. ${ }^{95-96}$ Demeclocycline can be used to manage chronic hyponatremia in patients with SIADH. The vaptans constitute a new class of drugs developed mainly used for the treatment of the hypervolemic and euvolemic forms of hyponatremia. They act through interfering with the antidiuretic effect of the hormone by competitively binding to $\mathrm{V}(2)$ receptors in the kidney. They were also found to be helpful in the treatment of the syndrome of inappropriate antidiuretic hormone (SIADH), especially when it is chronic and/or minimally symptomatic. ${ }^{97}$ Few studies studied the efficacy of vaptans in SIADH patients. They were of short duration however they did show that they are efficacious in increasing serum sodium concentrations. (98-100) Recently, two controlled trials of conivaptan used in a limited number of patients with euvolaemic hyponatraemia, mostly due to SIADH, showed that it is effective to increase free water clearance and to correct hyponatraemia. ${ }^{100-102}$

\section{Ectopic GHRH production}

Historical perspective: The first evidence of the existence of ectopic growth hormone secretion came from an old clinical observation noted in the 1960. Back then, it was noted that rare cases of carcinoids, especially those involving the bronchial tree, were associated with acromegaly. ${ }^{103-104}$ Then in 1976, it was documented that removal of a bronchial carcinoid did result in remission of the active disease in two acromegalic patients. It was proposed that these tumors were actually producing a substance with growth hormone releasing ability. ${ }^{104}$ Several other reports then followed. Then in 1982 three different molecular forms of GHRH were isolated, from pancreatic endocrine tumors in patients who had features of acromegaly, the longest being GHRH 1-44 NH2. Two other shorter peptides were also sequenced from the tumor extract, and they were GHRH 1-40 $\mathrm{OH}$ and GHRH 1-37 NH2 ${ }^{105-106}$ In 1984 it was discovered that the main biological activity of GHRH lies in its first 29 amino acids. ${ }^{107}$ It was also found, that those GHRH which were extracted from tumor tissue, had the same amino acid sequence as the GHRH produced from the hypothalamus. ${ }^{108}$ GHRH acts through binding to its receptor on somatotroph cells, hence activating adenylate cyclase resulting in an increase in intracellular cyclic AMP. Acromegaly results from an increase in IGF 1 secretion in peripheral tissues resulting from excessive secretion of GHRH. ${ }^{109-110}$ 


\section{Prevalence, presentation and diagnosis}

Ectopic growth hormone releasing hormone producing tumor account for $0.5-1 \%$ of all acromegaly patients. ${ }^{109-110}$ Many cases of ectopic GHRH were reported over the past 25 years. To prove the ectopic secretion of GHRH two criteria are needed. There must be a clear demonstration that this GHRH is actually produced by the tumor itself and the neoplastic cells from the tumor extract should stain positive for GHRH. The available GHRH radioimmunoassay enables the quantification of the amount of GHRH produced by the tumor. GHRH in peripheral blood is very high in patients with ectopic GHRH producing tumors as opposed to being normal or low in pituitary tumor secreting growth hormone. Although plasma GHRH higher than $300 \mathrm{ng} /$ liter is usually reported in patients with ectopic GHRH, however three cases of acromegaly due to ectopic secretion of GHRH have been reported with plasma GHRH between 100 and $300 \mathrm{ng} / \mathrm{liter}{ }^{109}$ The decrease in GHRH level upon tumor resection would further prove ectopic GHRH secretion however in many cases metastasis is present at the time of the diagnosis and surgery would not be a valid option. ${ }^{108-109}$ From the registry of the sole laboratory in France which measures plasma GHRH assays, 21 patients with ectopic GHRH secretion presenting with acromegaly were identified between 1983 and 2008. Their age ranged between 14-77 years and their median GHRH at diagnosis was found to be 548 (range 2709779) ng/liter. ${ }^{110}$

Two third of the tumors associated with ectopic GHRH production were carcinoids, especially of the lung and the gastrointestinal tract. Other reported tumors associated with ectopic GHRH secretion include pheochromocytoma ${ }^{111}$ and lung cystic adenoma. ${ }^{112}$ Among the lung carcinoids secreting GHRH, $78 \%$ were found to be located on the right side of the lung and the reason behind this observation is still unclear. In $35 \%$ of cases it was found that those lung carcinoids would have metastasis to the lymph nodes, liver and bones. ${ }^{113}$ Carcinoids arising from the gastrointestinal tract were mainly found in duodenum and jejunum. Pancreatic endocrine tumors were the second most common cause of ectopic GHRH production arising from the tail of the pancreas and these tumors are not normally aggressive in nature. ${ }^{114-115}$ Not all patients exhibit the acromegalic feature despite the fact that $30-60 \%$ of tumor cells of pancreatic endocrine tumors stained positive for GHRH. Moreover, there was no association between tumor size and acromegalic features.

However, in the France registry of patients with ectopic GHRH the primary neuroendocrine tumor was identified in 20 of 21 patients, 12 being pancreatic, seven bronchial and one appendicular. In these patients tumors were found to be large in size ranging between 10-80 $\mathrm{mm}$, was identified using computed tomography scan in 18 of those patients and by endoscopic ultrasound and somatostatin receptor scintigraphy in the remaining two patients. In this study it was found that somatostatin receptor scintigraphy had a similar sensitivity to computed tomography scan (81 vs. $86 \%$ ) Tumors were all well differentiated but $47.6 \%$ had metastasis at the time of diagnosis. 91 percent of those patients had their tumor completely removed and were considered to be in remission. The remaining patients were treated with somatostatin analogs. No correlations were found between GHRH levels and the tumor site or size or the presence or absence of metastases. Identification of increased plasma GHRH during the follow-up period was very highly predictive of recurrence. ${ }^{110}$

The duration of symptoms before the diagnosis was made was found to be similar between ectopic producing GHRH tumors and GH secreting pituitary adenomas. The indolent course of bronchial carcinoids led to delay in the diagnosis of patients with a mean of 10.6 years as opposed to pancreatic endocrine tumors, where the mean duration for the diagnosis was around five years. ${ }^{108-109}$ The classic manifestations of patients with ectopic GHRH producing tumors were found to be similar to those found in GH secreting pituitary adenomas. Ectopic co-secretion of ACTH was found in two of the reported cases of ectopic GHRH secretion by tumor. ${ }^{114}$ Coexistent hyperparathyroidism was found in six of the reported cases. ${ }^{115}$ High prolactin was found to be common in patients with ectopic GHRH production. ${ }^{116}$

\section{Treatment}

Surgical removal of the tumor producing this ectopic hormone is the mainstay of therapy especially when no metastasis is detected with the resolution of acromegaly being evident with the first weeks of therapy ${ }^{117-118}$ Systemic therapy is necessary in patients with metastatic or inoperable disease and this includes chemotherapy and somatostatin analogues. ${ }^{119-120}$

\section{Ectopic prolactin (PRL) production by tumors}

Historical perspective: First suggestion of ectopic production of PRL was by Rees et al., ${ }^{115}$ where a bronchial tumor was found to be actually producing the PRL hormone. ${ }^{115}$ Later, in 1986, a case of long standing gynecomastia associated with a hypernephroma, was reported in literature where serum PRL returned to normal after radical nephrectomy and remained so for 4 years without evidence of tumor recurrence. ${ }^{119}$

\section{Prevalence, presentation and diagnosis}

Prolactin was found to be ectopically produced by several cancers including malignant tumours of the lung, kidney, uterine, ovary, breast and colorectal cancer. ${ }^{15,119-125}$

There have been several reports recording high incidence of abnormal serum PRL in patients with uterine cervical carcinoma (around 30.8\%). It was even found that during early stages of cancer, the degree and incidence of elevation in serum PRL levels were much greater than those found for carcinoembryonic antigen (CEA), which is generally considered to be a circulating cervical tumor marker. ${ }^{120}$ These studies suggested that PRL may be a potential marker for detecting early occult tumors and could be a guide for therapy of cervical carcinoma. ${ }^{121}$

Another documentation of ectopic PRL secretion came from a prospective study, including 46 female patients with a confirmed diagnosis of breast cancer, who were followed up for a total of 5 years, where serum concentrations of prolactin were measured before and after the therapy at regular intervals during the observation period. Their PRL concentrations were compared to those of 40 healthy women and 33 women with other types of cancer (mostly colorectal and lung cancers), who served as control groups. It was found that baseline serum concentrations of PRL were higher in breast cancer patients than in healthy women $(16.9 \mathrm{ng} / \mathrm{ml} \mathrm{vs} 12.2 \mathrm{ng} / \mathrm{ml})$, and it was even higher when compared to patients with other cancers $(18.3 \mathrm{ng} / \mathrm{ml}$ vs $13.3 \mathrm{ng} / \mathrm{ml})$. Moreover, metastases developed in all patients with high PRL levels and in only a third of patients who had normal PRL levels. The average time interval to metastasis was significantly shorter in patients with higher serum concentrations of PRL as compared to those with very low levels (54.3 vs 6.1 months). In addition, in patients with metastatic breast cancer, high PRL levels before treatment correlated with the size of metastases. ${ }^{122}$ 
A study was done by Bhatavdekar et al to assess the role of PRL in patients with Dukes B and C colorectal carcinoma. It found that preoperative PRL and CEA were significantly higher in patients with colorectal carcinoma as compared to controls. Moreover, prolactin was the most significant independent prognostic factor influencing overall survival. A significantly higher incidence of increased PRL levels were found in tumors of patients with Dukes B and C disease and those with Dukes $C$ had even more increased PRL when compared to patients with Dukes B. This suggested de novo synthesis of PRL by tumor cells. ${ }^{123}$ This was even demonstrated by the presence of PRL m RNA expression in $88 \%$ of colorectal carcinoma patients. The carcinomas secreting PRL were shown to have a growth advantage and hence a worse prognosis. In view of its prognostic value the authors suggested that this may provide insights into the treatment of colorectal carcinoma. ${ }^{124}$ In a cross sectional study of 47 patients and 51 age and sex matched controls, serum PRL and CEA concentrations were assayed preoperatively using immunoradiometric assay kits. The study concluded that PRL may be a better tumor marker than CEA in patients with colorectal malignancy. ${ }^{125}$ Conversely, Baert et al did not find preoperative high PRL levels in a series of 32 patients with colorectal cancer. ${ }^{125}$ Furthermore, Indinnimeo et al. ${ }^{126}$ Found no hyperprolactinemia and/or PRL positive immunostaining in 30 patients with colorectal cancer and they suggested that PRL levels could not be used as prognostic marker in patients with colon cancer. ${ }^{126}$ Therefore, future prospective studies are needed to better understand the role of PRL as a prognostic factor in colorectal cancer.

\section{Other ectopic hormone syndromes}

\section{Tumor-induced osteomalacia}

A clinical syndrome, also known as oncogenic osteomalacia, characterized by the over production of fibroblast growth factor- 23 by certain tumors including mesenchymal tumors (osteoblastomas, giant cell osteosarcomas, hemangiopericytomas, hemangiomas, nonossifying fibromas), resulting in the triad of phosphaturia, hypophosphatemia, and low serum levels of 1,25-dihydroxy vitamin D with osteomalacia and moderate to severe proximal myopathy. It clinically mimics $\mathrm{X}$-linked or autosomal dominant hereditary hypophosphatemic rickets. Approximately 100 cases of tumorinduced osteomalacia have been reported. ${ }^{129-130}$ Patients affected are usually adults over the age of 30 , with a male-to-female ratio of 1.2:1. Diagnosis is very challenging. Laboratory and radiologic testing are essential for the diagnosis. Bone and indium-111 octreotide imaging are additional important diagnostic radiologic tools for small tumors not detected on routine physical examination or radiography. ${ }^{127-130}$ Oral or intravenous supplementation of phosphate combined with vitamin D therapy is generally recommended in addition to the complete surgical removal of the tumor. ${ }^{131-132}$

\section{Rare ectopic secreting tumors}

Polycythemia resulting from ectopic erythropoietin production is a rare clinical syndrome. Other less well-defined syndromes include production of thrombopoietin, leukopoietin, or colony-stimulating factor by certain types of tumors. These rare clinical syndromes have been usually identified in cerebellar hemangioblastoma, uterine fibroids, pheochromocytomas, ovarian and hepatic cancers. Treatment includes surgery, chemotherapy or phlebotomy. ${ }^{133}$

\section{Conclusion}

Paraneoplastic endocrine syndrome results from the ectopic production of hormones by different tumors. It is important to recognize this entity because it may lead to devastating clinical syndrome and may be the presentation of different tumors. In addition it significantly affects the prognosis of different tumor types. Important management of the original tumor including surgical resection or systemic therapy for inoperable disease is the mainstay of therapy.

\section{Acknowledgments}

None.

\section{Conflict of interest}

The author declares there is no conflict of interest.

\section{References}

1. Spinazze S, Schrijvers D. Metabolic emergencies. Crit Rev Oncol Hematol. 2006;58(1):79-89.

2. Yeung S, Gagel R. Endocrine Paraneoplastic Syndromes ("Ectopic" Hormone Production). Holland-Frei Cancer Medicine ( $6^{\text {th }}$ edn), 2003.

3. Metz S. Ectopic Hormones from Tumors. Ann Intern Med. 1975;83(1):117-118

4. Zondek H, Petrow H, Siebert W. Die Bedeutung der Calcium best immungimBlute fur die Dianose der Niereninsuffizienz. Z Klin Med. 1924;99:129-132.

5. Gutman A, Tyson T, Gutman E. Serum calcium, inorganic phosphorus, and phosphatase activity in hyperparathyroidism, Paget's disease, multiple myeloma and neoplastic disease of bones. Arch Intern Med. 1936;57(2):379-413

6. Albright F. Case records of the Massachusetts General Hospital (Case 27401). New England Journal of Medicine. 1941;225:789-791.

7. Martin TJ, Atkins D. Biochemical regulators of bone resorption and their significance in cancer. Essays in Medical Biochemistry. 1979;4:49-82.

8. Kukreja SC, Shermerdiak WP, Lad TE, et al. Elevated nephrogenous cyclic AMP-with normal serumparathyroid hormone levels in patients with lung cancer. J Clin Endocrinol Metab. 1980;51(1):167-169.

9. Ralston S, Gallacher SJ, Patel U, et al. Cancer associated hypercalcemia: morbidity and mortality. Clinical experience in 126 treated patients. Ann Intern Med. 1980;112(7):499-504.

10. Penel N, Dewas S, Hoffman A, et al. Cancer-associated hypercalcemia: validation of a bedside prognostic score. Support Care Cancer. 2009; 17(8):1133-1135.

11. Clines GA. Mechanisms and treatment of hypercalcemia of malignancy. Curr Opin Endocrinol Diabetes Obes. 2011;18(6):339-346.

12. Riggs BL, Arnaud CD, Reynolds JC, et al. Immunological differentiation of primary hyperparathyroidism from hyperparathyroidism due to non-parathyroid cancer. J Clin Invest. 1971;50(10):2079-2083.

13. Vacher-Coponat H, Opris A, Denizot A, et al. Hypercalcaemia induced by excessive parathyroid hormone secretion in a patient with a neuroendocrine tumour. Nephrol Dial Transplant. 2005;20(12):2832-2835.

14. Mundy GR, Edwards JR. PTH-Related Peptide (PTHrP) in Hypercalcemia. J Am Soc Nephrol. 2008;19(4):672-675.

15. Stewart AF. Clinical practice. Hypercalcemia associated with cancer. $N$ Engl J Med. 2005;352(4):373-379.

16. Budayr AA, Nissenson RA, Klein RF,et al. Increased serum levels of a parathyroid hormone-like protein in malignancy-associated hypercalcemia. Ann Intern Med. 1989;111(10):807-812.

17. Moseley JM, Gillespie MT. Parathyroid hormone-related protein. Critical Reviews in Clinical Laboratory Sciences. 1995;32:299-343. 
18. Yasuda H, Shima N, Nakagawa N, et al. Osteoclast differentiation factor is a ligand for osteoprotogerin/osteoclastogenesis inhibitory factor and identical to TRANCE/RANKL. Proc Natl Acad Sci U S A. 1998;95(7):3597-3602.

19. Lacey DL, Timms E, Tan HL, et al. Osteoprotogerin ligand is a cytokine that regulates osteoclast differentiation and activation. Cell. 1998;93(2):165-176.

20. Quinn JM, Elliott J, Gillespie MT, et al. A combination of osteoclas differentiation factor and macrophage-colony stimulating factor is sufficient for both human and mouse osteoclast formation in vitro. Endocrinology. 1998;139(10):4424-4427.

21. Grill V, Ho P, Body JJ, et al. Parathyroid hormone-related protein: elevated levels in both humoral hypercalcemia of malignancy and hypercalcemia complicating metastatic breast cancer. J Clin Endocrinol Metab. 1991;73(6):1309-1315.

22. Ralston SH, Fogelman I, Gardner MD, et al. Relative contribution of humoral and metastatic factors to the pathogenesis of hypercalcemia of malignancy. Br Med J (Clin Res Ed). 1984;288(6428):1405-1408.

23. Guise TA, Yin JJ, Taylor SD, et al. Evidence for a casual role of parathyroid hormone- related protein in the pathogenesis of human breast cancer-mediated osteolysis. J Clin Invest. 1996;98(7):1544-1549.

24. Martin TJ, Moseley JM. Mechanisms in the skeletal complications of breast cancer. Endocr Relat Cancer. 2000;7(4):271-284.

25. Iwamura M, Abrahamsson PA, Foss KA, et al. Parathyroid hormone related protein: a potential autocrine growth regulator in human prostate cancer cell lines. Urology. 1994;43(5):675-679.

26. Iwamura $\mathrm{M}$, Gershagen $\mathrm{S}$, Lapets $\mathrm{O}$, et al. Immunohistochemical localization of parathyroid hormone-related protein in prostatic intraepithelial neoplasia. Hum Pathol. 1995;26:797-801.

27. Roodman GD. Osteoclast function in Paget's disease and multiple myeloma. Bone. 1995;17(2 Suppl):57S-61S

28. Sezer O, Heider U, Zavrski I, et al. RANK ligand and osteoprotegerin in myeloma bone disease. Blood. 2003;101(6):2094-2098.

29. Hewison M, Kantorovich V, Liker HR, et al. Vitamin D-mediated hypercalcemia in lymphoma: evidence for hormone production by tumor-adjacent macrophages. J Bone Miner Res. 2003;18(3):579-582.

30. LeGrand SB, Leskuski D, Zama I. Narrative review: furosemide for hypercalcemia: an unproven yet common practice. Ann Intern Med. 2008;149(4):259-263

31. Hosking DJ. Cowley A, Bucknall CA. Rehydration in the treatment of severe hypercalcaemia. QJM: An International Journal of Medicine. 1981;50(4):473-481.

32. Bilezikian JP. Management of acute hypercalcemia. New England Journal of Medicine. 1992;326:1196-1203.

33. Fleisch H. Bisphosphonates. Pharmacology and use in the treatment of tumour-induced hypercalcaemia and metastatic bone disease. Drugs. 1991;42(6):919-944.

34. Body JJ. Rationale for the use of bisphosphonates in osteoblastic and osteolytic bone lesions. Breast. 2003;12(Suppl 2):S37-S44.

35. Bonjour JP, Rizzoli R. Antiosteolytic agents in the management of hypercalcaemia. Ann Oncol. 1992;3(8):589-590.

36. Coleman RE, Purohit OP. Osteoclast inhibition for the treatment of bone metastases. Cancer Treat Rev. 199;19(1):79-103.

37. Shipman CM, Rogers MJ, Apperley JF, et al. Bisphosphonate induces apoptosis in human myeloma cell lines: a novel anti-tumour activity. $\mathrm{Br}$ J Haematol. 1997;98(3):665-672.
38. Aparicio A, Gardner A, Tu Y, Savage A, et al. In vitro cytoreductive effects on multiple myeloma cells induced by bisphosphonates. Leukemia. 1998;12(2):220-229.

39. Yoneda T, Michigami T, Yi B, et al. Actions of bisphosphonates on bone metastasis in animal models of breast carcinoma. Cancer. 2000;88(12 Suppl):2979-2988.

40. Body JJ, Dumon JC. Treatment of tumor-induced hypercalcaemia with the bisphosphonate pamidronate: dose-response relationship and influence of the tumour type. Ann Oncol. 1994;5(4):359-363

41. Nussbaum SR, Younger J, Vandepol CJ, et al. Single-dose intravenous therapy with pamidronate for the treatment of hypercalcemia of malignancy: comparison of 30-, 60-, and 90-mg dosages. Am J Med. 1993;95(3):297-304

42. Purohit OP, Radstone CR, Anthony C, et al. A randomised double-blind comparison of intravenous pamidronate and clodronate in the hypercalcaemia of malignancy. Br J Cancer. 1995;72(5):1289-1293.

43. Major P, Lortholary A, Hon J, et al. Zoledronic acid is superior to pamidronate in the treatment of hypercalcaemia of malignancy: a pooled analysis of two randomized, controlled clinical trials. J Clin Oncol. 2001;19(2): 558-567.

44. Pecherstorfer M, Steinhauer EU, Rizzoli R, et al. Efficacy and safety of ibandronate in the treatment of hypercalcemia of malignancy: a randomized multicentric comparison to pamidronate. Support Care Cancer. 2003;11(8):539-547.

45. Otto S, Schreyer C, Hafner S, et al. Bisphosphonate-related osteonecrosis of the jaws - Characteristics, risk factors, clinical features, localization and impact on oncological treatment. J Craniomaxillofac Surg. 2012;40(4):303-309.

46. Schilcher J, Michaelsson K, Aspenberg P. Bisphosphonate Use and Atypical Fracture of the Femoral Shaft. N Engl J Med. 2011;364(18):17281737.

47. Matthew Perrone. FDA clears Amgen's bone-strengthening drug Prolia. Bio Science Technology. 2010.

48. Amgen's Denosumab Cleared by FDA for Second Indication. 2010.

49. Stopeck AT, Lipton A, Body JJ, et al. Denosumab compared with zoledronic acid for the treatment of bone metastases in patients with advanced breast cancer: a randomized, double-blind study. J Clin Oncol. 2010;28(35):5132-5139

50. Dietzek A, Connelly K, Cotugno M, et al. Denosumab in hypercalcemia of malignancy: A case series. J Oncol Pharm Pract. 2015;21(2):143147.

51. Hu MI, Glezerman I, Leboulleux S, et al. Denosumab for Patients With Persistent or Relapsed Hypercalcemia of Malignancy Despite Recent Bisphosphonate Treatment. J Natl Cancer Inst. 2003;105(18):14171420 .

52. Silva OL, Becker KL. Salmon Calcitonin in the Treatment of Hypercalcemia. Arch Intern Med. 1973;132(3):337-339.

53. Galante L, Joplin JF, MacIntyre I. The calcium lowering effect of salmon calcitonin in patients with Paget's disease. Clinical Science. 1973;44:605-610

54. Percival RC, Yates AJ, Gray RE, et al. Role of glucocorticoids in the management of malignant hypercalcaemia. Br Med J. 1984;289(6440):287.

55. Mundy GR, Rick ME, Turcotte R. Pathogenesis of hypercalcemiain lymphosarcoma cell leukemia. Role of an osteoclast activatin factor-like substance and a mechanism of action for glucocorticoid therapy. Am J Med. 1978;65(4):600-606. 
56. Isidori AM, Kaltsas GA, Pozza C, et al. (2006) The ectopic adrenocorticotrophin syndrome: clinical features, diagnosis, management and longterm follow-up. J Clin Endocrinol Metab. 2006;91(2):371-377.

57. Isidori AM, Lenzi A. Ectopic ACTH syndrome. Arq Bras Endocrinol Metabol. 2007;51(8):1217-1225.

58. Salgado LR, Fragoso MC, Knoepfelmacher M, et al. Ectopic ACTH syndrome: our experience with 25 cases. Eur J Endocrinol. 2006;155:725733.

59. Ilias I, Torpy DJ, Pacak K, et al. Cushing's syndrome due to ectopic corticotropin secretion: twenty years' experience at the National Institutes of Health. J Clin Endocrinol Metab. 2005;90(8):4955-4962.

60. Bhansali A, Walia R, Rana SS, et al. Ectopic Cushing's syndrome: Experience from a tertiary care Centre. Indian J Med Res. 2009;129(1):33-41.

61. Newell-Price J, Trainer P, Besser M, et al. The diagnosis and differential diagnosis of Cushing's syndrome and pseudo-Cushing's states. Endocr Rev. 1998;19(5):647-672.

62. Isidori AM, Kaltsas GA, Mohammed S, et al. Discriminatory value of the low-dose dexamethasone suppression test in establishing the diagnosis and differential diagnosis of Cushing's syndrome. J Clin Endocrinol Metab. 2003;88(11):5299-5306.

63. Grossman AB, Kelly P, Rockall A, et al. Cushing's syndrome caused by an occult source: difficulties in diagnosis and management. Nat Clin Pract Endocrinol Metab. 2006;2(11):642-647.

64. Castinetti F, Morange I, Dufour H, et al. Desmopressin test during petrosal sinus sampling: a valuable tool to discriminate pituitary or ectopic ACTH-dependent Cushing's syndrome. Eur J Endocrinol. 2007;157(3):271-277

65. Kaltsas GA, Giannulis MG, Newell-Price JD, et al. A critical analysis of the value of simultaneous inferior petrosal sinus sampling in Cushing's disease and the occult ectopic adrenocorticotropin syndrome. J Clin Endocrinol Metab. 1999;84(2):487-492.

66. Kalgikar AM, Chandratreya SA, Goel A, et al. Inferior petrosal sinus sampling in the diagnostic evaluation of Cushing's syndrome: K.E.M. experience. J Assoc Physicians India. 2005;53:685-688.

67. Torpy DJ, Chen CC, Mullen N, et al. Lack of utility of (111)In-pentetreotide scintigraphy in localizing ectopic ACTH producing tumors: followup of 18 patients. J Clin Endocrinol Metab. 1999;84(4):11861192.

68. Reincke M, Allolio B, Arlt W, et al. Comment on primary localization of an ectopic ACTH-producing bronchial carcinoid tumor by indium 111 pentetreotide scintigraphy. J Clin Endocrinol Metab. 1999;84(9):3399_ 3400 .

69. Zemskova MS, Gundabolu B, Sinaii N, et al. Utility of various functiona and anatomic imaging modalities for detection of ectopic adrenocorticotropin-secreting tumors. J Clin Endocrinol Metab. 2010;95(3):12071219.

70. Anaforog I, Ersoy K, Asık M, et al. Diagnosis of an ectopic adrenocorticotropic hormone secreting bronchial carcinoid by somatostatin receptor scintigraphy. Clinics. 20121;67(8):973-975.

71. Bell M, Myers T, Myers D. Expression of Proopiomelanocortin and Prohormone Convertase- 1 and -2 in the Late Gestation Fetal Sheep Pituitary. Endocrinology. 1998;139:12.

72. Blunt SB, Sandler LM, Burrin JM, Joplin GF. An Evaluation of the Distinction of Ectopic and Pituitary ACTH Dependent Cushing's Syndrome by Clinical Features, Biochemical Tests and Radiological Findings. Q J Med 77(283): 1113-1133.

73. Invitti C, Giraldi FP, de Martin M, et al. Diagnosis and management of Cushing's syndrome: results of an Italian multicentre study. Study group of the Italian Society of Endocrinology on the pathophysiology of the Hypothalamic-Pituitary-Adrenal Axis. J Clin Endocrinol Metab. 1999;84(2):440-448.
74. Oliver RL, Davis JR, White A. Characterisation of ACTH Related Peptides in Ectopic Cushing's Syndrome. Pituitary. 2003;6(3):119-126.

75. Raffin-Sanson ML, Massias JF, Dumont C, et al. High plasma proopiomelanocortin in aggressive adrenocorticotropin-secreting tumors. J Clin Endocrinol Metab. 1996;81(12):4272-4277.

76. Vieau D, Massias JF, Girard F, et al. Corticotrophin-like intermediary lobe peptide as a marker of alternate pro-opiomelanocortin processing in ACTH producing non-pituitary tumours. Clin Endocrinol (Oxf). 1989;31(6):691-700

77. Wajchenberg BL, Mendonca BB, Liberman B. Ectopic adrenocorticotropic hormone syndrome. Endocrine Reviews. 1994;15:752-787.

78. Krystallenia I, Alexandraki, Ashley B, et al. The ectopic ACTH syndrome. Reviews in Endocrine and Metabolic Disorders. 2010;11(2):117126.

79. Morris D, Grossman A. The medical management of Cushing's syndrome. Ann N Y Acad Sci. 2002;970:119-133.

80. Feelders RA, Hofland LJ, de Herder WW. Medical Treatment of Cushing's Syndrome: Adrenal-Blocking Drugs and Ketaconazole. Neuroendocrinology. 2010;92(Suppl 1):111-115.

81. Drake WM, Perry LA, Hinds CJ, et al. Emergency and prolonged use of intravenous etomidate to control hypercortisolemia in a patient with Cushing's syndrome and peritonitis. J Clin Endocrinol Metab. 1998;83(10):3542-3544.

82. Phlipponneau M, Nocaudie M, Epelbaum J, et al. Somatostatin analogs for the localization and preoperative treatment of an adrenocorticotropin-secreting bronchial carcinoid tumor. J Clin Endocrinol Metab. 1994;78(1):20-24.

83. de Bruin C, Feelders RA, Lamberts SW, et al. Somatostatin and dopamine receptors as targets for medical treatment of Cushing's Syndrome. Rev Endocr Metab Disord. 2009;10(2):91-102.

84. Schwartz WB, Bennett W, Curelop S, et al. A syndrome of renal sodium loss and hyponatremia probably resulting from inappropriate secretion of antidiuretic hormone. Am J Med. 1957;23(4):529-542.

85. Morton JJ, Kelly P, Padfield PL. Antidiuretic hormone in bronchogenic carcinoma. Clin Endocrinol (Oxf). 1978;9(4):357-370.

86. Terpstra TL, Terpstra TL. Syndrome of inappropriate antidiuretic hormone secretion: recognition and management. Medsurg Nurs. 2000;9(2):61-68.

87. Suzuki H, Tsutsumi Y, Yamaguchi K, et al. Small cell lung carcinoma with ectopic adrenocorticotropic hormone and antidiuretic hormone syndromes: a case report. Jpn J Clin Oncol. 1984;14(1):129-137.

88. Adrogue HJ. Consequences of inadequate management of hyponatremia. Am J Nephrol. 2005;25(3):240-249.

89. Smitz S. Hyponatremia and SIADH. CMAJ. 2002;167(5):449-450.

90. Hannon MJ, Thompson CJ. The syndrome of inappropriate antidiuretic hormone: prevalence, causes and consequences. Eur J Endocrinol. 2010;162(Suppl 1):S5-S12.

91. Hahn RG. Fluid absorption in endoscopic surgery. $\mathrm{Br} J$ Anaesth 2006;96(1) 8-20.

92. Osborn DE, Rao PN, Greene MJ, et al. Fluid absorption during transurethral resection. Br Med J. 1980;281(6254):1549-1550.

93. Oelkers W. Hyponatremia and inappropriate secretion of vasopressin (antidiuretic hormone) in patients with hypopituitarism. $N$ Engl J Med. 1989;321(8):492-496

94. Johnson BE, Damodaran A, Rushin J, et al. Ectopic production and processing of atrial natriuretic peptide in a small cell lung carcinoma cell line and tumor from a patient with hyponatremia. Cancer. 1997; $79(1): 35-44$ 
95. Maesaka JK, Batuman V, Yudd M, et al. Hyponatremia and hypouricemia: differentiation from SIADH. Clin Nephrol. 1990;33(4):174-178.

96. Cherrill DA, Stote RM, Birge JR, et al. Demeclocycline Treatment in the Syndrome of Inappropriate Antidiuretic Hormone Secretion. Ann Intern Med. 1975;83(5):654-656.

97. Robertson GL. Vaptans for the treatment of hyponatremia. Nat Rev Endocrinol. 2011;7(3):151-161.

98. Decaux G. Long-term treatment of patients with inappropriate secretion of antidiuretic hormone by the vasopressin receptor antagonist conivaptan, urea, or furosemide. Am J Med. 2001;110(7):582-584.

99. Saito T, Ishikawa S, Abe K, et al. Acute aquaresis by the nonpeptide arginine vasopressin (AVP) antagonist OPC-31260 improves hyponatremia in patients with syndrome of inappropriate secretion of antidiuretic hormone (SIADH). J Clin Endocrinol Metab. 1997;82(4):1054-1057.

100. Zeltser D, Rosansky S, van Rensburg H, et al. Assessment of the efficacy and safety of intravenous conivaptan in euvolemic and hypervolemic hyponatremia. Am J Nephrol.2007;27(5):447-457.

101. Verbalis JG, Zeltser D, Smith N, et. Assessment of the efficacy and safety of intravenous conivaptan in patients with euvolaemic hyponatraemia: subgroup analysis of a randomized, controlled study. Clin Endocrinol (Oxf); 2008;69(1):159-168.

102. Zietse R, Lubbe NVD, Hoorn EJ. Current and future treatment options in SIADH. NDT Plus. 2009;2(Suppl 3):iii12-iii19.

103. Dabek FT. Bronchial carcinoid tumour with acromegaly in two patients. J Clin Endocrinol Metab. 1974;38(2):329-333.

104. Sonksen PH, Ayres AB, Braimbridge M, et al. Acromegaly caused by pulmonary carcinoid tumours. Clin Endocrinol (Oxf). 1976;5(5):503513.

105. Guillemin R, Brazeau P, Bohlen P, et al. Growth hormone-releasing factor from a human pancreatic tumor that caused acromegaly. Science. 1982;218(4572):585-587.

106. Rivier J, Spiess J, Thorner M, et al. Characterization of a growth hormone-releasing factor from a human pancreatic islet tumour. Nature. 1982;300(5889):276-278.

107. Ling Esch F, Bohlen FP, Brazeau P, et al. Isolation, primary structure, and synthesis of human hypothalamic somatocrinin: growth hormonereleasing factor. Proc Natl Acad Sci U S A. 1984; 81(14):4302-4306.

108. Losa M, von werder K. Pathophysiology and Clinical Aspects of GHreleasing Hormone Syndrome. Clin Endocrinol (Oxf). 1997;47(2):123135 .

109. Agha, Farrell L, Downey P, Keeling P, et al. Acromegaly secondary to growth hormone releasing hormone secretion. Ir J Med Sci. 2004;173(4): 215-216.

110. Garby L, Caron P, Claustrat F, et al. Clinical Characteristics and Outcome of Acromegaly Induced by Ectopic Secretion of Growth HormoneReleasing Hormone (GHRH): A French Nationwide Series of 21 Cases. J Clin Endocrinol Metab. 2012;97(6):2093-2104.

111. Roth KA, Wilson DM, Eberwine J, et al. Acromegaly and Pheochromocytoma: A Multiple Endocrine Syndrome Caused by a plurihormonal adrenal medullary tumor. J Clin Endocrinol Metab. 1986;63(6):14211426 .

112. Southgate HJ, Archbold GP, el-Sayed ME, et al. Ectopic release of GHRH and ACTH from an adenoid cystic carcinoma resulting in acromegaly and complicated by pituitary infarction. Postgrad Med J. 1988;64(748):145-148.

113. Butler PW, Cochran CS, Merino MJ, et al. Ectopic growth hormone-releasing hormone secretion by a bronchial carcinoid tumor: clinical experience following tumor resection and long-acting octreotide therapy. Pituitary. 2010;15(2):260-265.
114. Leveston SA, McKeel DW, Buckley PJ, et al. Acromegaly and Cushing's syndrome associated with a foregut carcinoid tumor. J Clin Endocrinol Metab. 1981;53(4):682-689.

115. Rees LH, Bloomfield GA, Rees GM, et al. Multiple hormones in a bronchial tumor. J Clin Endocrinol Metab. 1974;38(6):1090-1097.

116. Spero M, White EA. Resolution of acromegaly, amenorrhea-galactorrhea syndrome, and hypergastrinemia after resection of jejunal carcinoid. J Clin Endocrinol Metab. 1985;60(2):392-395.

117. van Hoek M, Hofland LJ, de Rijke YB, et al. Effects of somatostatin analogs on a growth hormone-releasing hormone secreting bronchial carcinoid, in vivo and in vitro studies. J Clin Endocrinol Metab. 2009;94(2):428-433.

118. Zatelli MC, Maffei P, Piccin D, et al. Somatostatin analogs in vitro effects in a growth hormone-releasing hormone secreting bronchial carcinoid. J Clin Endocrinol Metab. 2005;90(4):2104-2109.

119. Stanisic TH, Donovan J. Prolactin secreting renal cell carcinoma. J Urol. 1986;136(1):85-86.

120. Hsu CT, Yu MH, Lee CY, et al. Ectopic production of Prolactin in uterine cervical carcinoma. Gynecol Oncol. 1992;44(2):166-171.

121. Hoffman WH, Gala RR, Kovacs K, et al. Ectopic prolactin secretion from a gonadoblastoma. Cancer. 1987;60(11):2690-2695.

122. Mujagic Z, Mujagic H. Importance of serum prolactin determination in metastatic breast cancer patients. Croat Med J. 2004; 45(2):176-180.

123. Bhatavdekar JM, Patel DD, Chikhlikar PR, et al. Ectopic production of prolactin by colorectal adenocarcinoma. Dis Colon Rectum. 2001;44(1):119-127.

124. Ahmad RS, Hosein MZ, Mehrnush M. Plasma prolactin in patients with colorectal cancer. BMC Cancer. 2004;4:97.

125. Baert D, Matthys C, Gillardin JP, et al. Prolactin and colorectal cancer: is there a connection? Acta Gastroenterol Belg. 1998;61(4):407-409.

126. Indinnimeo $\mathrm{M}$, Cicchini $\mathrm{C}, \mathrm{Memeo} \mathrm{L}$, et al. Plasma and tissue prolactin detection in colon carcinoma. Oncol Rep. 2001;8(6):1351-1353.

127. Folpe AL, Fanburg-Smith JC, Billings SD, et al. Most osteomalaciaassociated mesenchymal tumors are a single histopathologic entity: an analysis of 32 cases and a comprehensive review of the literature. Am J Surg Pathol. 2004;28(1):1-30.

128. Shimada T, Mizutani S, Muto T, et al. Cloning and characterization of FGF23 as a causative factor of tumor-induced osteomalacia. Proc Natl Acad Sci U S A. 2001;98(11):6500-6505.

129. Edmister KA, Sundaram M. Oncogenic osteomalacia. Seminars in Mus culoskeletal Radiology. 2002;6:191-196.

130. Garcia CA, Spencer RP. Bone and In-111 octreotide imaging in oncogenic osteomalacia: a case report. Clin Nucl Med. 2000;27(8):582-583.

131. Nuovo MA, Dorfman HD, Sun CC. Tumor-induced osteomalacia and rickets. Am J Surg Pathol. 1989;13(7):588-599.

132. Reyes-Mugica M, Arnsmeier SL, Backeljauw PF, et al. Phosphaturic mesenchymal tumor-induced rickets. Pediatr Dev Pathol. 2000;3(1):6169.

133. Suzuki M, Takamizawa S, Nomaguchi K, et al. Erythropoietin synthesis by tumour tissues in a patient with uterine myoma and erythrocytosis. $\mathrm{Br}$ J Haematol. 2001;113(1):49-51. 